\title{
Influence of Flow Blowing Agent on the Properties of Aerated Concrete Variable Density and Strength
}

\author{
V. Galdina ${ }^{(\bowtie)}$, E. Gurova, P. Deryabin, M. Rashchupkina, \\ and I. Chulkova \\ Department of Building Structures, Ogarev Mordovia State University, \\ Saransk, Russia \\ example@yandex.ru
}

\begin{abstract}
We presented the effect of gasifier flow on gas release kinetics and basic properties of aerated concrete with variable traverse density and strength. We found optimal consumption of gasifier for manufacturing of aerated concrete with variatropic properties from expanded clay sand, wherein we obtained aerated concrete with a strength of $1.42 \mathrm{MPa}$ at an average density of $414 \mathrm{~kg} / \mathrm{m}^{3}$.
\end{abstract}

Keywords: Cellular concrete $\cdot$ Aerated concrete $\cdot$ Blowing consumption · Bloating $\cdot$ Gas release kinetics

\section{Introduction}

The scientists and technologists should develop a technology of new generation of cellular concrete with a higher strength and frost-resistance at a low average density.

\section{Methods and Approaches}

The production of concrete products in a closed mold can be related to new methods. Works by Chernov and Zavadsky are important at the present stage of production of aerated concrete. Their studies are mainly based on preparation of gas concrete mix in the mold with a hollow cap (without holes), or small holes in side and top faces of the mold (Chernov et al. 1983; Chernov 2003; Zavadsky 2005; Zavadsky 2001; Chernov 2002; Zavadsky, Kosach 1999).

The properties of aerated concrete with variable traverse density and strength of products are influenced by the following factors: area of surface of a cover; fluidity of mix; consumption and type of blowing agent; fill level of mix in the mold; type, flow rate and surface area of silica component and binder. 


\section{Results and Discussion}

The formation of a cellular structure and gas-concrete products in an individual mold was carried out as follows: gas-concrete mix was prepared, poured into a mold closed by a cover with a circular hole in the center of the mold (The method..., 2015).

The essence of formation of a cellular structure of concrete of variable traverse density and durability is as follows. Hydrogen releases when an alkaline component binds with aluminum, which results in blowing of viscoplastic mass. The blowing mix, having reached the internal surface of the cover with a circular hole, meets a barrier on the way and swells up on the way of the weakest resistance (through the hole), and on the periphery of the product there is a self-consolidation of aerated concrete due to overpressure. As a result, the pressing gas with more than $0.1 \mathrm{kgf} / \mathrm{cm}^{2}$ and presence of the closed cover surface at the time of a blowing results in less dense and more porous products in the mid-range of the composite and denser, stronger - on the periphery.

The known formulations in production of gas-concrete products by traditional technology, in particular a gas developing agent consumption, are not absolutely correct for manufacturing of products in the closed mold since the raised gas developing agent consumption is necessary for effective self-consolidation of exemplars. In this regard it is necessary to reveal its influence on a kinetics of gas emission of the mix and main properties of aerated concrete.

$\mathrm{V} / \mathrm{T}=0.5$ was applied to aerated concrete on the basis of expanded clay sand with mix spread at Southard viscosimeter $30 \mathrm{~cm}$. Gazobetolyuks gas paste and earlier chosen area of the closed cover surface with the round section equal to $71 \%$ was applied as gas developing agent. The mix was poured up to $70 \%$ of the mold height.

The nature of a flatulence of the mix up to the cover in the period of time from 5 to $20 \mathrm{~min}$ at all gas-concrete mix was identical, different only by the amount of gas developing agent. Process of an aerogenesis in all mixtures practically finishes in 20 30 min (Fig. 1).

The highest limit of compression strength is observed for samples produced at a gasifier flow $1000 \mathrm{~g}$ per $\mathrm{m}^{3}$ of the mix. As a result of the chemical reaction the released hydrogen swells the mix which reaches the edge of the mold, where it meets an obstacle of cover and is pressed on the way of the weakest resistance through a circular hole in the cover, whereby mostly form crusts and increase strength of samples during compression. When the flow reduces to $800 \mathrm{~g}$ the strength is reduced on average by $30 \%$. This is a result of low flow of the gasifier, and the mix during swelling is not sufficient for self-sealing along the periphery, which is confirmed by gas release kinetics, which reaches the inner surface of the cover only in 20-22 min and the final height of swelling $35 \%$. Since one of the main objectives is not only to obtain aerated concrete with a relatively high compressive strength, but also with reduced average density index, the optimum flow rate is from 1100 to $1300 \mathrm{~g}$ per $\mathrm{m}^{3}$. 


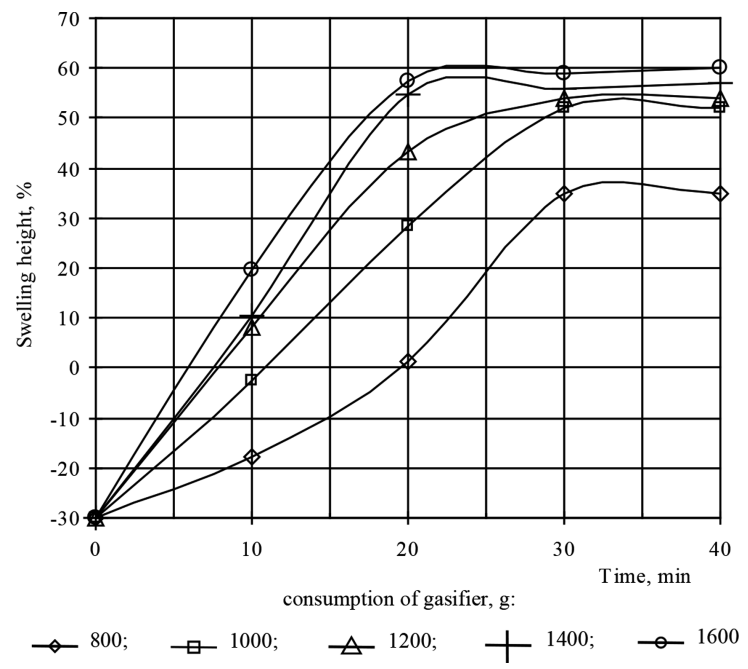

Fig. 1. Kinetics of gas emission of mix on the basis of expanded sand

Aerated concrete, prepared in the mold with a circular hole in the cover on expanded clay aggregate with the strength $1.42 \mathrm{MPa}$ at an average density $414 \mathrm{~kg} / \mathrm{m}^{3}$ (Fig. 2), was obtained at a flow rate equal to $1,200 \mathrm{~g}$ of blowing agent per $\mathrm{m} 3 \mathrm{of}$ mix, which corresponds to D500 brand strength. The gassing process also takes about 25$30 \mathrm{~min}$, after which the height of the crusts is $50-54 \%$ (Fig. 2).

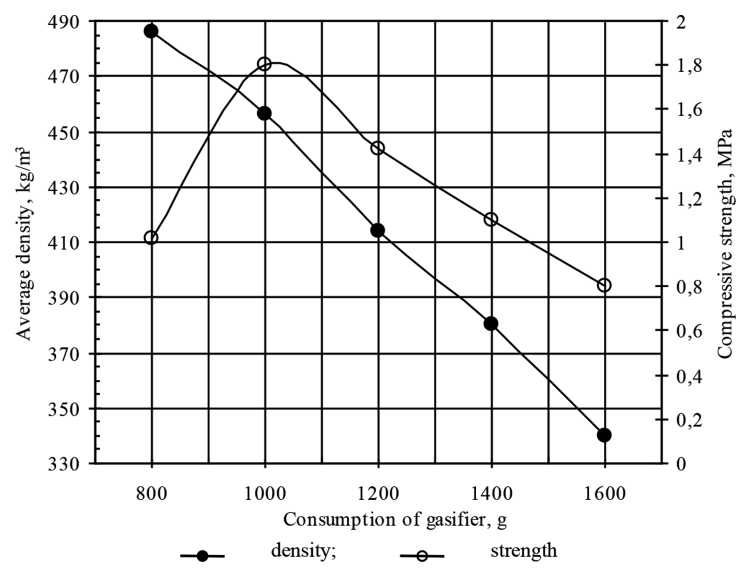

Fig. 2. The effect of the gasifier consumption on the average density and strength of aerated concrete based on expanded clay sand 


\section{Conclusions}

We determined the optimal flow of gas agent on the basis of expanded clay sand equal to $1100-1300 \mathrm{~g}$ per $\mathrm{m}^{3}$, at which the aerated concrete with a durability of $1.42 \mathrm{MPa}$ at an average density of $414 \mathrm{~kg} / \mathrm{m}^{3}$ that corresponds to D500 brand was produced. At the same time the process of aerogenesis continues 25-30 min, after which the height of top crust is $50-54 \%$.

Advantage of technology of aerated concrete with variatropic properties is a high stability of density of cellular concrete depending only on the accuracy of the gravimetric feeders measuring components. At the same time not only density, but also durability, deformability, heat conductivity and other properties are stabilized. The increased dispersion of operational parameters, inherent to all cellular concretes, is excluded.

Development of new and combination of already known methods of pore making in mass and also application of processing methods for products with variatropic properties at formation allow producing one and two-layer wall products of various configuration, sizes and required heat-shielding and operational properties.

\section{References}

Chernov AN (2003) Auto-frettage in aerated concrete technology. Constr Mater 11:22-23

Chernov AN (2002) Cellular concretes. Publishing house of SUSU, Chelyabinsk, $111 \mathrm{p}$

Chernov AN, Kozhevnikova LP, Khmelev SV, Tsarkov VV, Danilyuk MA, Moiseev EI, Stepanova ZA (1983) Technology of cellular concrete products with compacted surface layer. Constr Mater 8:12-13

The method of producing aerated concrete and the raw mix for its preparation. Patent of the Russian Federation P. Deryabin. No. 2560009 of July 202015

Zavadsky VF (1999) An integrated approach to solving the problem of thermal protection of walls of heated buildings. Constr Mater 2:7-8

Zavadsky VF (2001) Variants of wall constructions with the use of effective heaters Novosibirsk: NGASU, $52 \mathrm{p}$

Zavadsky VF, Kosach AF (2005) Wall materials and products. SibADI Publishing House, Omsk, $254 \mathrm{p}$

Open Access This chapter is licensed under the terms of the Creative Commons Attribution 4.0 International License (http://creativecommons.org/licenses/by/4.0/), which permits use, sharing, adaptation, distribution and reproduction in any medium or format, as long as you give appropriate credit to the original author(s) and the source, provide a link to the Creative Commons license and indicate if changes were made.

The images or other third party material in this chapter are included in the chapter's Creative Commons license, unless indicated otherwise in a credit line to the material. If material is not included in the chapter's Creative Commons license and your intended use is not permitted by statutory regulation or exceeds the permitted use, you will need to obtain permission directly from the copyright holder.

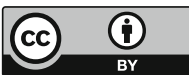

